\title{
DIAGNÓSTICO SITUACIONAL DOS RESÍDUOS SÓLIDOS URBANOS NO MUNICÍPIO DE CUITÉ-PB: UMA APLICAÇÃO DO SISTEMA DE INDICADOR DE SUSTENTABILIDADE PRESSAี̃O - ESTADO - IMPACTO - RESPOSTA (P-E-I-R)
}

\section{SITUATIONAL ANALYSIS OF URBAN SOLID RESIDUE IN THE MUNICIPALITY OF CUITÉ-PB: AN APPLICATION OF THE SUSTAINABILITY INDICATOR SYSTEM PRESSURE - STATE - IMPACT - RESPONSE (P-E-I-R)}

\author{
Sandra Sereide Ferreira da Silva ${ }^{1}$; Gesinaldo Ataíde Cândido ${ }^{2}$; Ângela Maria Cavalcanti Ramalho ${ }^{3}$ \\ ${ }^{1}$ Universidade Federal de Campina Grande - UFCG - Campina Grande - Brasil \\ sandrasereide@yahoo.com.br \\ ${ }^{2}$ Universidade Federal de Campina Grande - UFCG - Campina Grande - Brasil \\ gacandido@uol.com.br \\ ${ }^{3}$ Universidade Federal de Campina Grande - UFCG - Campina Grande - Brasil \\ angelaramalho@oi.com.br
}

\begin{abstract}
Resumo
As sociedades modernas vêm enfrentando várias questões ambientais, como o aquecimento global, esgotamento dos recursos não-renováveis, poluição dos recursos hídricos, dentre outros. Uma destas questões que se destaca é o problema dos resíduos sólidos. A partir destas considerações, o objetivo do artigo é elaborar um diagnóstico situacional dos resíduos sólidos urbanos no município de Cuité- PB, através da aplicação do sistema de indicador de sustentabilidade pressão-estadoimpacto-resposta (P-E-I-R). Em termos metodológicos, o estudo pode ser caracterizado como descritivo e exploratório conduzido sob a forma de um estudo de caso. Os dados foram obtidos, a partir da realização da obtenção de dados primários junto aos atores sociais e institucionais com algum tipo de vínculo com o problema dos resíduos sólidos no município, associado à análise de dados secundários e a observação não-participante. Os resultados obtidos apontam que do total de 36 variáveis, apenas 6 delas puderam ser analisadas positivamente, correspondendo a um percentual de 16, 7\%, o que revela uma situação de insustentabilidade ambiental. Tal situação demanda a necessidade de mudança nas políticas públicas, nas práticas de gestão das empresas e um maior nível de cidadania da população para reverter tal situação.
\end{abstract}

Palavras-chave: ambiente; sustentabilidade; resíduos sólidos.

\section{Introdução}

A segunda metade do Século XX, até os nossos dias, as sociedades modernas vêm padecendo e enfrentando várias questões ambientais, como o aquecimento global, esgotamento dos recursos não-renováveis, poluição dos recursos hídricos, dentre outros. No entanto, em meio a esses 
múltiplos problemas, um deles se destaca por sua amplitude: os resíduos sólidos. Mais usualmente cognominado de lixo, os resíduos sólidos roubaram a cena nesse começo de Século, tendo em vista que seus impactos negativos ultrapassam as questões ambientais e têm implicações econômicas, sociais, políticas e institucionais nas mais diversas áreas.

Adentrando-se nesse cenário, em nenhuma outra etapa do desenvolvimento humano, como a atual, gerou-se tanto lixo (resíduo) e, racionalmente, prejudicou-se tanto a saúde das populações humanas quanto o próprio meio ambiente. Não obstante a geração de resíduos provenientes das atividades humanas faça parte da própria história do homem, é a partir da segunda metade do Século XX, com os novos padrões de consumo da sociedade industrial, que essa realidade vem crescendo em ritmo superior à capacidade de carga e absorção pela natureza. Aliado a isso, o avanço tecnológico das últimas décadas, se, por um lado possibilitou conquistas no campo das ciências, por outro, contribuiu para o aumento da diversidade de produtos com componentes e materiais de difícil degradação e maior toxicidade.

Mucelin e Bellini (2008) enfatizam que o consumo cotidiano de produtos industrializados é responsável pela contínua produção de lixo. Nas cidades, a produção é de tal intensidade que não é possível conceber uma cidade sem considerar a problemática gerada pelos resíduos sólidos, desde a etapa da geração até a disposição final. De forma enfática, os autores ainda afirmam que é inevitável a geração de lixo nas cidades devido à cultura do consumo. Esses resíduos representam a potencialização da degradação dos recursos naturais de um dado espaço geográfico. Tal situação leva a pressões sobre o meio ambiente, entre essas pressões, está a destruição de recursos não renováveis e a utilização intensiva de recursos renováveis. O que corrobora para a comprovação de que o crescimento das cidades e a crescente ampliação das áreas urbanas têm contribuído para o aumento de impactos ambientais negativos, assim como o crescimento de vulnerabilidades urbanas e, ainda, impactos socioeconômicos nas finanças públicas e privadas.

As pressões sobre o meio ambiente na cidade envolvem um amplo e complicado conjunto de fatores de ordem econômica, social e política. Já o estado em que se encontra o meio ambiente, assim como os impactos sócio-ambientais listados, tem cobrado da sociedade o comprometimento na formulação e implementação de planos, programas e projetos direcionados a alcançarem à melhoria da qualidade de vida da população na cidade, como resposta à conjuntura dessa situação. Representados pelas dinâmicas socioeconômica, demográfica e de ocupação do território ao longo dos anos, influenciam as condições atuais de seus recursos ambientais e influencia, por sua vez, o futuro e a sustentabilidade da cidade.

Diante da observação desta problemática, especialmente, quanto aos resíduos sólidos e análise das relações feitas, a partir de acesso a dados secundários, forma realizadas entrevistas com 
atores sociais e institucionais, com algum tipo de vínculo com o problema dos resíduos sólidos, além das inferências feitas pelos pesquisadores baseadas em observação não participante.

Este artigo tem como objetivo principal elaborar um diagnóstico situacional dos resíduos sólidos urbanos no município de Cuité- PB, através da aplicação do sistema de indicador de sustentabilidade pressão-estado-impacto-resposta (P-E-I-R).

Desenvolvido pela OECD (1993) para o estudo de problemas ambientais, o P-E-I-R foi melhorado pelo PNUMA em 2007, e vem sendo aceito e adotado internacionalmente. Neste modelo, as pressões sobre o ambiente são reduzidas àquelas causadas pela ação do homem, desconsiderando às provenientes da ação da natureza. Consubstanciando-se nos chamados sistemas de informação ambiental, configura um sistema de armazenamento de informação de distintas fontes, servindo de alicerce para a elaboração de políticas de gestão ambiental. Tem como escopo o conceito de causalidade em que as atividades humanas exercem pressões sobre o ambiente alterando a qualidade e a quantidade de recursos naturais, ou seja, alterando o seu estado. A sociedade responde a essas alterações por meio de políticas ambientais, econômicas ou setoriais.

Em termos metodológicos, este estudo apresenta-se, quanto aos fins, como descritivo, exploratório e, quanto aos meios, é avaliado como um estudo de caso. É resultado do processo de consulta aos diversos atores institucionais envolvidos direta ou indiretamente com os resíduos sólidos urbanos no município de Cuité-PB. No que se refere às variáveis do modelo PEIR, estas foram analisadas tomando-se por base a ausência ou presença das mesmas para com a sustentabilidade, levando-se em consideração a dimensão analisada. Com o escopo de melhor dimensionar a análise, as variáveis que compuseram as dimensões foram sistematizadas e igualmente analisadas na sequencia: descrição da variável, justificativa da escolha da variável, fonte de dados utilizados para a sua comprovação, assim como os resultados encontrados no município em análise.

Além deste conteúdo introdutório, o artigo apresenta a seguinte estrutura: fundamentação teórica, envolvendo os conceitos relativos à Desenvolvimento Sustentável e Indicadores de Sustentabilidade, Resíduos Sólidos Urbanos e posteriormente o modelo de análise da pesquisa (Modelo P-E-I-R). A parte seguinte aborda os procedimentos metodológicos utilizados. Em seguida são expostas a apresentação e análise dos resultados complementada pelas considerações finais do estudo.

\section{Fundamentação Teórica}

\subsection{Desenvolvimento Sustentável e Indicadores de Sustentabilidade}

A ideia de desenvolvimento sustentável teve sua origem preliminarmente atrelada à noção de desenvolvimento, consubstanciada na ótica de crescimento, até o surgimento do conceito do que 
seja desenvolvimento sustentável. Tal conceito é fundamento no Relatório de Brundtland -1987 Nosso Futuro Comum, o qual consagrou até então a afirmativa de que o desenvolvimento sustentável é aquele que "atende às necessidades do presente sem comprometer a possibilidade de as gerações futuras atenderem suas próprias necessidades" (CMMAD, 1987).

Esse relatório despertou a atenção do planeta no que se refere à problemática ambiental, bem como a necessidade urgente de buscar alternativas de desenvolvimento econômico no sentido da sustentabilidade, ou seja, formas que não reduzissem os recursos naturais e nem prejudicasse o meio ambiente. Com base nesse relatório, foram definidos três princípios básicos a serem seguidos, desenvolvimento econômico, proteção ambiental e equidade social, atrelados à indispensabilidade de mudanças tecnológicas e sociais.

Para Sachs (2004) o desenvolvimento na perspectiva da sustentabilidade vai bem além da multiplicação da riqueza. É uma condição necessária, porém não suficiente, nem um objetivo em si mesmo. É uma maneira de se conseguir uma vida melhor, mais feliz e mais completa para todos. Complementando esta linha de pensamento, Cavalcanti (2003) aponta que, existem limitações do ponto de vista que é cada vez mais generalizada a consciência de nosso dever com relação às nossas gerações futuras e a limites que a natureza e o meio ambiente nos impõem. Nessa visão, tem-se que tomar consciência acerca da degradação entrópica, a qual tudo na Terra é submetido. Por outro prisma, a inclusão das questões ecológicas nas decisões econômicas conduz a um reconhecimento de que as consequências ecológicas da maneira como a população faz uso dos recursos naturais do planeta estão integradas ao modelo de desenvolvimento utilizado.

Van Bellen (2004) assegura que o conceito de desenvolvimento sustentável alcançou um destaque inusitado a partir da década de 1990, tornando-se um dos termos mais empregados para se definir um novo modelo de desenvolvimento. O autor ressalta a importância da mensuração deste tipo de desenvolvimento com base em indicadores.

Estas medidas são úteis como auxiliares aos tomadores de decisão a compreender melhor, em termos operacionais, o que o conceito de desenvolvimento sustentável significa, funcionando como ferramentas de explicação para auxiliar a escolha de alternativas políticas, direcionando para metas relativas à sustentabilidade, tendo em vista que as ferramentas fornecem um senso de direção aos tomadores de decisão e, quando escolhem entre alternativas de ação, funcionam como ferramentas de planejamento. E por fim, para avaliar o grau de sucesso no alcance das metas estabelecidas referentes ao desenvolvimento sustentável, sendo estas medidas ferramentas de avaliação. 
Diante desse contexto, permite-se assegurar que os indicadores de sustentabilidade compõem importantes parâmetros para enfocar a realidade, dentro de um contexto multidisciplinar, tendo por finalidade fornecer informações imprescindíveis para a tomada de decisão.

\subsection{O Modelo Pressão Estado Impacto Resposta}

Ao longo dos anos muitos esforços têm sido empreendidos por parte de alguns países e instituições internacionais para a construção de indicadores característicos para o monitoramento e análise das condições ambientais. Nesse sentido, uma das primeiras experiências de desenvolvimento de indicadores ambientais surgiu por empreendimento da Organização para a Cooperação e o Desenvolvimento Econômico (OCDE) que, em 1993, criou uma metodologia que tem como escopo fornecer um primeiro mecanismo de monitoramento do progresso ambiental dos países que fazem parte da instituição. Esse sistema usa o modelo pressão-estado-resposta (PER), um dos sistemas que vem adquirindo cada vez mais destaque internacional.

O modelo PER (Pressão-Estado-Resposta) desenvolvido pela OECD (1993), para o estudo de indicadores ambientais globais vem sendo aceito e adotado internacionalmente. Nesse modelo, as pressões sobre o ambiente são reduzidas àquelas causadas pela ação do homem, desconsiderando as provenientes da ação da natureza.

Contudo, embasando-se no avanço da degradação ambiental, houve a necessidade de incorporar no modelo PER um elemento que o caracterizasse no sentido de avaliar o impacto gerado pela urbanização sobre o meio. Foi a partir desse objetivo que se introduziu o componente "I" - "Impacto" no modelo desenvolvido.

No novo modelo, o Programa das Nações Unidas e Meio Ambiente - PNUMA (2007), entre outras atribuições, o define como a resultância entre as pressões ocasionadas pelas atividades humanas e o meio ambiente. Essa nova metodologia implica na identificação das atividades antrópicas que afetam o meio ambiente, passando a ser representada pela sigla PEIR, PressãoEstado-Impacto-Resposta, de acordo com o Quadro 1 a seguir.

Quadro 1 - Dimensões do Modelo PEIR

\begin{tabular}{|c|l|}
\hline $\begin{array}{c}\text { Dimensões do } \\
\text { Modelo }\end{array}$ & \multicolumn{1}{c|}{ Características } \\
\hline Pressão & $\begin{array}{l}\text { diz respeito a algumas atividades e processos urbanos que atuam sobre o meio ambiente e que } \\
\text { produzem mudanças ambientais como, volume dos resíduos sólidos gerados no município, } \\
\text { crescimento da população da cidade, aumento dos geradores de resíduos, dentre outros; }\end{array}$ \\
\hline Estado & $\begin{array}{l}\text { condição ou qualidade do meio ambiente envolvendo aspectos como qualidade do ar, dos } \\
\text { corpos hídricos prejudicados pela disposição inadequada de resíduos, área de terras degradadas } \\
\text { pela disposição de resíduos, etc. }\end{array}$ \\
\hline Impacto & $\begin{array}{l}\text { refere-se ao efeito do estado ou condição do meio ambiente sobre a saúde e a qualidade de vida } \\
\text { humana, a economia urbana, os ecossistemas, etc. serão contemplados aspectos como: destino } \\
\text { final dos resíduos sólidos nos lixões, ocasionando diversos efeitos sobre a qualidade do meio } \\
\text { ambiente; índice de doenças envolvendo as populações no entorno do lixão, dentre outros }\end{array}$ \\
\hline
\end{tabular}




\begin{tabular}{|l|l|}
\hline & aspectos. \\
\hline Resposta & ações desenvolvidas com o objetivo de prevenir impactos ambientais negativos, tendo como \\
& meta corrigir danos ambientais ou conservar os recursos naturais. Logo, respostas podem \\
& incluir: ações regulatórias, normas e legislações como subsídios para melhorar a problemática \\
& dos resíduos sólidos do município, neste caso, a adoção do presente plano de gerenciamento \\
& integrado de resíduo sólido poderá ser uma resposta na tentativa de solucionar a problemática \\
& ambiental do município. \\
\hline
\end{tabular}

Fonte: Adaptado OECD (1993), PNUMA (2007)

Com base nesse modelo, dependendo do objetivo para o qual o PEIR é utilizado, este pode ser facilmente adaptado de acordo com a necessidade de uma maior precisão ou com características particulares. Ressalte-se que, dependendo das relações ponderadas, alguns termos podem estar presentes em mais de uma dessas categorias, tendo em vista a relação direta entre essas dimensões, ao passo em que uma entusiasma conjuntamente a outra.

O PEIR é caracterizado também como um programa de comunicação que tem como objetivo sensibilizar sobre questões ambientais, proporcionando opções para ações, através das quais se torna possível dentre outras atribuições, fazer análise de medidas corretivas, adotar novos rumos no enfrentamento dos problemas ambientais, assim como identificar competências e níveis de responsabilidade dos agentes sociais comprometidos. Neste ponto de vista, insere-se a problemática ambiental urbana gerada pelos resíduos sólidos, em que a busca constante por um novo paradigma para a correta gestão vislumbra-se como um dos maiores desafios do começo deste novo milênio, tendo em vista que as soluções até então encontradas e colocadas em prática, ainda não são capazes de se mostrarem como forma única e universalmente aceita.

Corroborando com esse enfoque, permite-se pontuar que a questão dos resíduos sólidos urbanos constitui para a sociedade atual um grave problema socioambiental, que decorre dos modelos insustentáveis de produção e consumo, e que ocasiona impactos ambientais e de saúde pública que necessitam ser enfrentados. Outro aspecto a ser considerado também se refere à gestão e a disposição imprópria dos resíduos sólidos, tendo em vista que estes provocam impactos socioambientais, sobretudo: a deterioração do solo, o comprometimento dos corpos d'água e mananciais, o reforço para a poluição do ar e a propagação de vetores de valor sanitário nos centros urbanos, catação de lixo em situação insalubre nos logradouros públicos e nas áreas de disposição final.

Diante desse contexto, percebe-se que a produção excessiva de resíduos sólidos e a maneira insustentável de utilização dos recursos naturais se configuram numa coerência destrutiva e num risco para a sustentabilidade do planeta, cuja reversão implica na transformação das atitudes e práticas individuais e coletivas de toda sociedade. 


\subsection{Resíduos Sólidos Urbanos (RSUs)}

O termo resíduo sólido, quase sempre sinônimo de lixo, deriva do latim "residuu” e quer dizer sobra de substâncias, acrescido de sólido para se diferenciar de resíduos líquidos ou gasosos. Independentemente da designação, a temática envolvendo essas palavras se destaca em nível global como uma das mais sérias realidades com as quais os seres humanos têm convivido desde a época da Revolução Industrial, tendo em vista a cumulatividade dos danos causados ao meio ambiente e as populações como um todo.

A problemática gerada pelo aumento da quantidade de resíduos sólidos na maioria dos países e, particularmente em determinadas regiões vem se agravando em decorrência de inúmeras causas ao longo dos anos, dentre as quais: acelerado crescimento populacional com concentração intensiva nas áreas urbanas, desenvolvimento industrial e alterações nos hábitos de consumo.

Além do acréscimo das desigualdades sociais, culturais e econômicas provocadas pela expansão do consumismo, outro fator assume o papel de vilão absoluto: o destino final dos materiais utilizados no processo de fabricação dos produtos que, ao passo que novos são colocados no mercado e adquiridos pelas pessoas, os "antigos" são deixados de lado, contribuindo de forma danosa e prejudicial ao meio ambiente, que na maioria das cidades, em todo o mundo são descartados e jogados a céu aberto sem qualquer controle ambiental, o que causa por consequência, danos prejudiciais e irreparáveis ao meio ambiente, tendo em vista a composição pesada dos materiais utilizados na fabricação dos mesmos. Com isso, o meio ambiente torna-se cada vez mais prejudicado e por implicação, a qualidade de vida, torna-se um desafio muito preocupante e difícil de ser sustentado em longo prazo.

Frente a essa percepção, Silva (2008) afirma que as divulgações feitas pelos meios de comunicação a respeito da questão ambiental, envolvendo os resíduos sólidos, representam apenas parte das variáveis que contribuem com o desequilíbrio ambiental, que, por conseguinte, levam ao desequilíbrio da saúde das populações.

Complementando esse pensamento, Oliveira (2002) coloca que o enfrentamento do problema lixo extrapola a simples eliminação dos chamados lixões. É importante considerar desde a sua origem, quando não é descartado nas residências e locais de lazer ou trabalho, até o destino final. Isto porque durante muito tempo a maioria das administrações públicas do Brasil, permitiu-se “enganar" pelos chamados custos zeros dos lixões. Visivelmente, sempre foi mais barato descartar o lixo em qualquer vala, distante dos centros urbanos e comumente próximos às periferias. Entretanto, com o passar dos anos, foi-se percebendo que o custo dessa disposição inadequada tornava-se muito maior do que o que se imaginava; contaminação dos recursos hídricos, do solo, aumento das desigualdades sociais, assim como as pesadas multas, de acordo com a legislação ambiental vigente, dentre outros agravantes. 
Diante dessa situação, muitos municípios, especificamente os maiores, buscaram alternativas para reverter tal situação, tendo em vista serem os maiores geradores bem como os que sofrem as maiores fiscalizações e especulações dos órgãos de opinião pública. Já para os pequenos municípios coube reproduzir os métodos utilizados pelos grandes, que nem sempre foram apropriados à sua realidade espacial e econômica, ou simplesmente por serem pequenos, continuaram a ignorar o problema.

No que se refere à problemática do destino final, esta assume uma amplitude preocupante. Mais de 80\% dos municípios conforme dados do IBGE (2002) vazam seus resíduos em locais a céu aberto, em cursos d'água ou em áreas ambientalmente protegidas, a maioria com a presença de catadores - entre eles crianças -, delatando os problemas sociais que a má gestão do lixo acarreta.

Quando os resíduos sólidos não tratados apropriadamente são depositados sem as devidas cautelas em lixões a céu aberto ou até em cursos d'água, há o risco de contaminação de mananciais de água potável, sejam superficiais ou subterrâneos e a dispersão de doenças por intermédio de vetores que se multiplicam nos locais de disposição de papel, dentre outros resíduos criam um ambiente favorável para a sua proliferação.

Tendo em vista a importância da temática, somada a quantidade de variáveis envolvidas, as discussões para a correta gestão dos resíduos sólidos acabam por trilharem caminhos diferentes. De um prisma, cada vez mais pesquisadores das mais diversas áreas e ONGs - Organizações NãoGovernamentais têm certeza de que para se resolver a problemática é imprescindível reconsiderar os atuais padrões de consumo e descarte, instigar o consumo consciente e a necessidade de aprimorar as condições de vida e trabalho das pessoas que têm na catação do lixo uma forma de sobrevivência.

Por outro prisma, boa parte das prefeituras das mais diferentes regiões do Brasil, após deparar-se com as constantes pressões do Ministério Público e dos órgãos ambientais de fiscalização, inicia uma busca por alternativas para a resolução da problemática. Entretanto, deparase com entraves financeiros, carência de qualificação técnica do quadro de servidores municipais, bem como descontinuidade administrativa e política das ações. Outra parte dessas prefeituras vê a questão do lixo tão somente como um problema que se resolve através de tecnologias especiais, como a utilização da logística reversa e de máquinas para a coleta e destino final, que possam desobrigar essas prefeituras de tais penalidades. Depreende-se de atitudes como essas, a formação de uma dualidade entre as questões ambientais e os modelos insustentáveis de produção e consumo assim como as alternativas locais implementadas pelas municipalidades, necessitando, portanto de uma eficaz solução para essa questão.

Em face desse enfoque, pesquisas de caráter empírico capazes de gerar indicadores seguros que possam embasar estudos e tomadas de decisão são decisivos e indispensáveis; isto porque um 
sistema de indicadores determina os temas e os parâmetros que são preferenciais para se realizar a avaliação do desempenho. Na área da gestão ambiental é irrefutável a proficuidade que se tem em trabalhar com informações que tornem clara a situação.

No entanto, a grandeza de informações ambientais atualmente existentes e a precisão de se dispor de dados confiáveis como contribuição para a tomada de decisões, torna indispensável à constituição de um sistema para seu manejo e difusão de forma a estabelecer um marco conceitual capaz de prestar-se como referência. Isto contribui para o reconhecimento das pressões desempenhadas pela ação antrópica ocasionada ao meio ambiente, do estado em que se encontra esse meio ambiente, dos impactos provocados, assim como das respostas que a sociedade e o poder público podem oferecer.

\section{Procedimentos Metodológicos}

A pesquisa realizada caracteriza-se como um estudo exploratório e descritivo conduzido sob a forma de um estudo de caso realizado no município de Cuité-PB.

O modelo metodológico PEIR foi estruturado de maneira que pressão-estado-impactoresposta compusessem as dimensões do modelo e estas foram compostas por variáveis, elencadas da seguinte forma:

Dimensão Pressão: variáveis de pressão direta: volume dos resíduos sólidos per capita; volume dos resíduos sólidos (toneladas por ano); coleta do lixo diretamente para o lixão e, resíduos dos serviços de saúde (RSS) destinados sem tratamento. Variáveis de pressão indireta: coleta de lixo nos bairros; crescimento da população da cidade; aumento dos geradores de resíduos; existência de catadores nas ruas; moradias na unidade de disposição dos resíduos e, queima de resíduos a céu aberto.

Dimensão Estado: qualidade do ar (drenagem de gases); qualidade do ar (aproveitamento dos gases); qualidade dos corpos hídricos; existência de instalações administrativas; existência de base impermeabilizada; drenagem do chorume; recirculação de chorume; tratamento de chorume na mesma área da unidade; monitoramento ambiental; frequência da cobertura dos resíduos sólidos; existência de licenciamento ambiental; mapeamento da área degradada.

Dimensão Impacto: doenças envolvendo as populações no entorno do lixão; infecção e contaminação hospitalar; poluição dos recursos hídricos; má utilização do espaço; alagamento das vias públicas; poluição visual.

Dimensão Resposta: existência de associação ou cooperativa; tratamento de resíduos sólidos urbanos; existência de política pública; participação da população da gestão do lixo; estudos sobre 
impactos ambientais; providência de melhoramento com relação ao destino final do lixo; parceria com outros municípios; ações regulatórias.

Quanto às variáveis do modelo PEIR, ressalve-se que apenas na dimensão Estado foi utilizada fonte de consulta bibliográfica para sua classificação, nas outras três dimensões a classificação teve por base, elaboração própria dos autores deste estudo. Quanto aos parâmetros de análise, em todas as dimensões foi com base no conhecimento próprio dos autores, tomando-se por base a ausência ou presença das mesmas para com a sustentabilidade, levando-se em consideração a dimensão analisada.

Advirta-se que na variável volume dos resíduos sólidos per capita, o parâmetro de avaliação obedece ao seguinte critério: será considerada favorável a sustentabilidade quando o volume dos resíduos sólidos per capita $\leq$ a $0,8(\mathrm{~kg} / \mathrm{hab}$./dia) e será desfavorável quando o volume dos resíduos sólidos per capita >.0,8(kg/hab./dia). Tome-se como parâmetro semelhante para a variável, volume dos resíduos sólidos (toneladas por ano), tendo em vista que para se obter este valor, usa-se primeiramente o volume per capita. $\mathrm{O}$ valor 0,8 refere-se à definição dada pelo Instituto Brasileiro de Administração Municipal (2001), das faixas mais utilizadas da geração per capita de resíduos sólidos no Brasil. Este valor é utilizado para cidades de tamanho médio e que sua população varia de 30 a 500 mil habitantes.

No se refere à escolha das variáveis para a avaliação da qualidade ambiental do Município de Cuité-PB, quanto aos resíduos sólidos urbanos, estas obedeceram aos seguintes critérios: Confiabilidade dos dados: respeitou-se o caráter científico da informação; Relação com os problemas ambientais: deu-se prioridade à representatividade da informação para o estudo; Utilidade para o usuário: considerou-se a aplicabilidade da informação; Relevância: a informação coletada possui seriedade política, setorial e temática claramente pautada com as questões ambientais.

No que se refere à população pesquisada, esta foi constituída por todos os habitantes do Município de Cuité-PB, ou seja: 20.834 habitantes. Contudo, a amostra utilizada foi nãoprobabilística estratificada por acessibilidade, composta por 147 habitantes, estes denominados de atores sociais e institucionais e que têm ligação direta ou indireta com a problemática ambiental pesquisada. A amostra consultada obedeceu à seguinte divisão: representantes do poder público foram consultados dez atores; moradores de bairros foram consultados noventa atores; representantes de associações e escolas; consultaram-se dez atores; agentes de limpeza; fazem parte da estatística, dez atores; catadores: foram consultados sete atores; comerciantes, compuseram a pesquisa, vinte atores.

Para subsidiar as entrevistas aos atores sociais e institucionais, foi elaborada uma lista sistematizada de problemas relacionados à gestão de RSU, elencadas conforme as dimensões com 
as respectivas variáveis que compõem o Sistema de Indicador de Sustentabilidade Pressão-EstadoImpacto-Resposta (PEIR); de maneira a identificar as formas de entendimento desses atores a respeito do tema, para a partir dessas informações possibilitar a geração de novos indicadores para a pesquisa, assim como estudos futuros. Para tanto, foram consultados também diversos documentos de origem institucional, assim como levantamento junto à Prefeitura Municipal acerca das condições atuais da gestão dos resíduos sólidos urbanos no Município contexto deste estudo.

Quanto à coleta de dados, esta foi realizada de março de 2008 a abril de 2010 e obedeceu a sequência: levantamento teórico empírico dos principais problemas relacionados à gestão pública dos resíduos sólidos urbanos; entrevista com os principais atores sociais e institucionais do município de Cuité-PB para identificação da problemática em questão e das prioridades locais a serem mitigadas, assim como observação in loco dos principais questionamentos levantados para a consolidação deste estudo.

Concluída a coleta dos dados da pesquisa, com a geração dos indicadores do modelo PEIR, estes foram organizados e elencados conforme o enfoque de cada dimensão, levando-se em consideração a triangulação das informações, ou seja, dados primários, dados secundários e a observação não-participante do pesquisador foram interceptados de forma que possibilitassem uma ponderação das variáveis que constituem o sistema de indicador de sustentabilidade. Terminada a análise das variáveis individuais, deu-se sequência à análise de cada dimensão do modelo PEIR, ou seja, Pressão-Estado-Impacto-Resposta, assim como a análise do conjunto agregado das dimensões, conforme os mesmos critérios estabelecidos para a avaliação.

O resultado desse método foi o diagnóstico situacional da questão ambiental analisada, neste caso, em especial, dos resíduos sólidos urbanos no município de Cuité-PB.

\section{Apresentação, diagnóstico situacional e análise dos resultados}

Resultado do processo de consulta aos diversos atores institucionais envolvidos direta ou indiretamente com os Resíduos Sólidos Urbanos no Município de Cuité-PB; é apresentada nesta parte do estudo a aplicação do Sistema de Indicador de Sustentabilidade Pressão-Estado-ImpactoResposta, objetivando ressaltar os problemas selecionados por todos os atores, bem como pela observação in loco realizada.

Tais problemas foram identificados como prioritários para a gestão local, uma vez que refletem os desafios enfrentados pelos gestores. Adverte-se para tanto, a dificuldade de mensuração do número de atores sociais envolvidos. Igualmente, torna-se pertinente pontuar que a definição das variáveis que compõem o Indicador PEIR fora definida e estabelecida com base em consulta a diversos autores pertinentes à temática em epígrafe, uma vez que por se tratar de um indicador que 
retrata a qualidade ambiental de determinada localidade ou situação, o mesmo é considerado variável, dependendo, portanto, da realidade pesquisada.

Por permitir a identificação de problemas e a visualização de prioridades, o diagnóstico é uma fase essencial em qualquer estudo. Na temática específica resíduos sólidos, é imprescindível para avaliar a situação do sistema de limpeza urbana, assim como sua inclusão na administração local. No âmbito de um estudo de característica participativa, como é o caso deste, o diagnóstico tem proeminência ainda maior, visto que, quando bem embasado, compõe um documento fundamental de ação tendo por finalidade delinear as estratégias de ação.

Num primeiro momento, o diagnóstico consubstanciou-se em visitas preliminares ao objeto de estudo, complementadas por subsídios adquiridos ao longo dos meses de realização deste trabalho. Para tanto, nesta fase inicial foram observados alguns elementos comuns ao município, dentre os quais: problemas de saúde da população, ocasionados pela precariedade dos serviços de saneamento e pela ausência de ações de educação sanitária; deficiência básica nos sistemas de limpeza pública, tanto no campo funcional como no administrativo, expondo de início a inexistência de controles operacionais como uma fiscalização adequada, ausência de aterro sanitário, com disposição final em lixões, sem qualquer procedimento de tratamento; resíduos de unidades de saúde coletados e destinados juntamente com os resíduos comuns (domiciliar e doméstico); predomínio de embalagens e plásticos notadamente as PET dispostas a céu aberto nos lixões da cidade, alto índice de não aproveitamento doméstico da matéria orgânica; resíduos especiais de serrarias acarretando queimadas e poluição atmosférica; varrição das ruas e logradouros apenas nas ruas centrais; necessidade de legislação específica para regular a limpeza urbana; deficiência de comunicação do serviço de limpeza com a comunidade; carência de programa contínuo de educação ambiental, dentre outros.

Frente a essa circunstância e para corroborar num estudo dinâmico, e que reportasse de fato a real conjuntura do que estava acontecendo no município de Cuité-PB, no que se refere aos resíduos sólidos urbanos, necessitava-se de uma metodologia que tivesse dentre algumas atribuições, aquela que permitisse uma visão participativa e que possibilitasse congregar os múltiplos olhares sobre a questão ambiental em consonância com os princípios do desenvolvimento sustentável.

A participação dos distintos setores da sociedade, bem como dos vários atores sociais e institucionais foi considerada como a principal diretriz de todo o estudo. Contudo, para contextualizar essas múltiplas visões, tornou-se preciso recorrer aos vários catedráticos que fundamentam este assunto. Após pesquisar esses conhecedores da temática, resolveu-se elencar os muitos questionamentos de forma que pudesse no final ter uma visão do todo e quando necessário, de forma segmentada. Partindo-se desse consenso, houve a distribuição dos questionamentos 
similares acoplados por dimensão e estas compostas por variáveis que no final iriam compor o todo denominado indicador pressão-estado-impacto-resposta.

De forma geral, os autores consultados enfatizam que as variáveis empregadas para se definir o padrão de qualidade ambiental de um determinado espaço geográfico são muito debatidas, pois o que é apreciado ou desvalorizado no meio ambiente para determinar a sua qualidade está ancorado da compreensão de cada cidadão, até mesmo do pesquisador e do planejador das ações.

Assim, acredita-se que não há concordância quanto à utilização de variáveis que definem a qualidade ambiental urbana, ficando o pesquisador competente a determinar os constitutivos (ou variáveis) que possibilitem melhor alcançar a análise do espaço geográfico em estudo. Ainda assim, frise-se também que a utilização de uma proposta metodológica adaptada a realidade local para se aplicar ao estudo da qualidade ambiental urbana, desde que corresponda aos interesses do pesquisador e responda aos objetivos estabelecidos na pesquisa é de extrema relevância no contexto da transparência das informações.

Convém ressaltar, entretanto, a importante tarefa de consulta pública à comunidade local que o pesquisador e o planejador devem assumir ao executar um trabalho, pesquisa ou empreendimento que carreguem no seu bojo uma preocupação com a qualidade ambiental de um determinado local, vez que somente com atitudes nesse âmbito é que qualquer ação será concretizada com êxito. Neste contexto e com base nas dimensões Pressão, Estado, Impacto e Resposta estudados neste estudo, o Quadro 2 apresenta a situação ambiental diagnosticada em Cuité-PB.

Do conjunto de variáveis de cada dimensão estudada, percebe-se que do total de 36 variáveis desta análise, apenas 6 delas $(16,7 \%)$ apresentaram resultados positivos (FAVORÁ VEIS), sendo 3 delas pertencentes à Dimensão Pressão e as outras 3 a Dimensão Resposta. Na dimensão pressão, apenas as variáveis volume dos resíduos sólidos per cápita, volume dos resíduos sólidos (toneladas por ano) e coleta de lixo nos bairros foram analisadas como positivas. No que se refere à dimensão resposta, somente as variáveis: existência de política pública, estudos sobre impactos ambientais e ações regulatórias tiveram avaliação positiva. 
Quadro 2 - Modelo PEIR

\begin{tabular}{|c|c|c|c|c|}
\hline $\begin{array}{c}\text { DIMEN- } \\
\text { SÕES }\end{array}$ & & VARIÁVEIS & FAVORÁVEL & DESFAVORÁVEL \\
\hline \multirow{10}{*}{$\begin{array}{l}0 \\
i \frac{1}{2} \\
0 \\
\frac{1}{\alpha} \\
0\end{array}$} & \multirow{4}{*}{ 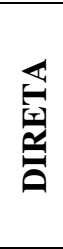 } & Volume dos resíduos sólidos per capita & & \\
\hline & & Volume dos resíduos sólidos (toneladas por ano) & & \\
\hline & & Coleta do lixo diretamente para o lixão & & \\
\hline & & $\begin{array}{l}\text { Resíduos dos serviços de s } \\
\text { aúde (RSS) destinados sem tratamento }\end{array}$ & & \\
\hline & \multirow{6}{*}{ 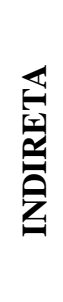 } & Coleta de Lixo nos Bairros & & \\
\hline & & Crescimento da população da cidade & & \\
\hline & & Aumento dos geradores de resíduos & & \\
\hline & & Existência de catadores nas ruas & & \\
\hline & & Moradias na unidade de disposição dos resíduos & & \\
\hline & & Queima de resíduos a céu aberto & & \\
\hline \multirow{12}{*}{ 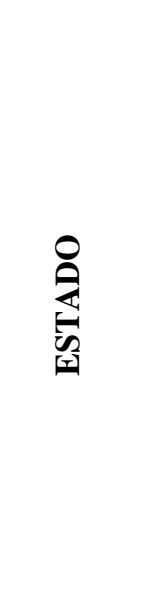 } & \multicolumn{2}{|c|}{ Qualidade do ar (drenagem de gases) } & & \\
\hline & \multicolumn{2}{|c|}{ Qualidade do ar (aproveitamento dos gases) } & & \\
\hline & \multicolumn{2}{|c|}{ Qualidade dos corpos hídricos } & & \\
\hline & \multicolumn{2}{|c|}{ Existência de instalações administrativas } & & \\
\hline & \multicolumn{2}{|c|}{ Existência de base impermeabilizada } & & \\
\hline & \multicolumn{2}{|c|}{ Drenagem do chorume } & & \\
\hline & \multicolumn{2}{|c|}{ Recirculação de chorume } & & \\
\hline & \multicolumn{2}{|c|}{ Tratamento de chorume na mesma área da unidade } & & \\
\hline & \multicolumn{2}{|c|}{ Monitoramento ambiental } & & \\
\hline & \multicolumn{2}{|c|}{ Frequência da cobertura dos resíduos sólidos } & & \\
\hline & \multicolumn{2}{|c|}{ Existência de Licenciamento ambiental } & & \\
\hline & \multicolumn{2}{|c|}{ Mapeamento da área degradada } & & \\
\hline \multirow{6}{*}{ 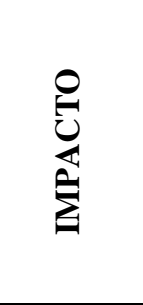 } & \multicolumn{2}{|r|}{ Doenças envolvendo as populações no entorno do lixão } & & \\
\hline & \multicolumn{2}{|r|}{ Infecção e Contaminação Hospitalar } & & \\
\hline & \multicolumn{2}{|c|}{ Poluição dos recursos hídricos } & & \\
\hline & \multicolumn{2}{|c|}{ Má utilização do espaço } & & \\
\hline & \multicolumn{2}{|c|}{ Alagamento das vias públicas. } & & \\
\hline & \multicolumn{2}{|c|}{ Poluição visual } & & \\
\hline \multirow{8}{*}{ 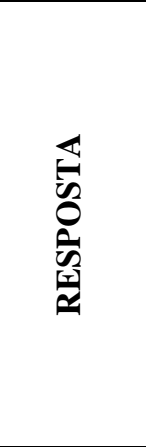 } & \multicolumn{2}{|c|}{ Existência de associação ou cooperativa } & & \\
\hline & \multicolumn{2}{|c|}{ Tratamento de resíduos sólidos urbanos } & & \\
\hline & \multicolumn{2}{|c|}{ Existência de política pública } & & \\
\hline & \multicolumn{2}{|c|}{ Participação da população da gestão do lixo } & & \\
\hline & Estu & os sobre impactos ambientais & & \\
\hline & $\begin{array}{l}\text { Proy } \\
\text { do } 1\end{array}$ & $\begin{array}{l}\text { dência de melhoramento com relação ao destino final } \\
\text { o. }\end{array}$ & & \\
\hline & Parc & ria com outros municípios & & \\
\hline & Açõ & regulatórias & & \\
\hline
\end{tabular}

Fonte: Autoria Própria, 2010; Dimensões Pressão - Impacto e Resposta - Dimensão Estado (as variáveis foram adaptadas do SNIS 2006)

Em virtude desta análise, a avaliação realizada quanto às pressões, estado e impactos ocasionados ao meio ambiente pela má disposição de resíduos, e tendo em vista a degradação antrópica dos espaços observados ocorrido nos últimos anos na cidade de Cuité-PB, pode-se afirmar que a situação dos resíduos sólidos no município é precária. Neste sentido, é necessário que a 
sociedade passe a cobrar das instâncias competentes providências no sentido de mitigar esta situação, a partir de ações direcionadas em busca de soluções para o problema, considerando que, a área onde funciona o lixão inclui nascentes, riachos e áreas úmidas em geral, visto que essas áreas garantem funções vitais e têm proeminente importância sócio-ambiental para o município.

O que se tem até agora são medidas de significância ainda pequenas e que demonstram tão somente a fragilidade da qualidade ambiental e a dificuldade de se atingir níveis satisfatórios de sustentabilidade. Ainda assim, são muitas as provocações e as aflições da sociedade em face dos diagnósticos ambientais e suas implicações na saúde da população. Os riscos à saúde pública, advindos dos resíduos sólidos, emanam da influência mútua de uma multiplicidade de fatores que compreendem aspectos ambientais, ocupacionais e de consumo, dentre outros.

Ademais, medidas como coleta seletiva, implantação de aterro sanitário, extinção dos chamados lixões, reciclagem, dentre outras são, sobretudo, medidas paliativas. Os geradores, que somos todos nós, devemos ser conscientes e ter em mente que é urgente diminuir o consumo supérfluo, evitando desperdícios, separar o material reciclável na origem (residência, indústria, comércio), reaproveitando os produtos ao máximo para que o exercício do consumo consciencioso seja uma alternativa viável e eficaz.

Para tanto, é de fundamental seriedade a tomada de consciência de que os atuais níveis de consumo dos países industrializados não podem ser conseguidos por todos os povos que habitam na Terra e, muito menos, pelas gerações futuras, sem destruição do capital natural.

Logo, permite-se assegurar diante do exposto que o gerenciamento dos resíduos sólidos tem uma relação com o processo de conscientização da população quanto aos padrões de consumo, da seriedade e do reaproveitamento dos múltiplos materiais e da prática da coleta seletiva. Neste enfoque, a educação ambiental é a condição que deve estar presente e em conformidade com as políticas públicas de redução e destinação do lixo, não somente no município de Cuité-PB, mas em todos os lugares que se façam presentes a necessidade de consumo.

\section{Considerações Finais}

Finalizando este estudo, cabe sintetizar as observações realizadas, corroborando a correlação entre a investigação procedida e os objetivos propostos, bem como recomendar a continuidade de trabalhos na mesma linha filosófica, que permitam aclarar em minúcia ou complementar os estudos, que por dificuldade temporal ou estrutural não tenham sido com este realizado.

Em relação ao objetivo proposto, que encaminhava no sentido de elaborar um diagnóstico dos problemas dos resíduos sólidos urbanos no Município de Cuité-PB, utilizando o Sistema de Indicador de Sustentabilidade Pressão-Estado-Impacto-Resposta P-E-I-R; a experiência da pesquisa contribuiu para o entendimento de que, um diagnóstico ambiental, que ponha em foco a 
coordenação das interdependências locais, parece constituir-se em condição para a obtenção de resultados proeminentes e duradouros, neste campo, ou seja, para a efetividade da gestão ambiental municipal.

As dimensões de pressão e de estado sobressaíram-se da análise como aptas a contribuírem para o progressivo aperfeiçoamento do processo decisório ambiental, inclusive pela visão sincrônica e diacrônica que propiciam. Neste contexto, as utilizações das variáveis que compõem as dimensões pressão e estado podem contribuir para a promoção da efetividade da gestão ambiental municipal, apreendida como a abrangência de objetivos sociais relevantes, na visão da própria comunidade ou de seus representantes.

O lixo constitui questão sanitária grave em Cuité-PB, que ainda utiliza vazadouros a céu aberto, visivelmente, sobrepujando ou ameaçando a habilidade de auto-regeneração do sistema água-solo-ar, corroborando um grau de poluição e degradação ambiental aglomerado, maléfico à vida, à saúde e à economia da população, que reage, cobrando, pelas vias disponíveis, as contrapartidas devidas, além de mais responsabilidade e eficiência do gestor público municipal.

A deficiência de dados sistemáticos e de registros de informações na Prefeitura Municipal de Cuité-PB e de seus representantes governamentais constituíram-se numa limitação deste trabalho, isto porque, a ausência de dados estatísticos ou de um Sistema de Informação Ambiental restringem por demais o planejamento urbano e ambiental e abre-se mão de uma respeitável ferramenta, que são os indicadores, para direcionar o processo de tomada de decisões, e que muitas vezes na falta deste, acaba-se por consumir os limitados recursos disponíveis em áreas menos prioritárias.

A construção de um Sistema de Indicadores Ambientais, baseado no marco analítico Pressão-Estado-Resposta proposto pela OECD, e complementado pelo PNUMA com a dimensão Impacto para se avaliar a qualidade ambiental numa esfera municipal, indicou resultados condizentes com a realidade do município de Cuité-PB, mesmo utilizando-se um número relativamente pequeno de variáveis ambientais.

Ainda assim, a democratização das informações obtidas tem como finalidade possibilitar uma melhor atuação do poder público na formulação de propostas para melhoria dessa qualidade ambiental diagnosticada. Neste argumento, a preparação e a operacionalização de um sistema de indicadores ambientais municipais são medidas que se revelaram importantes para que se tenham informações adequadas a diagnóstico, prognóstico, monitoramento e avaliação de políticas públicas, contribuindo para a confirmação da primeira hipótese.

Dessa maneira, a gestão ambiental por suas características próprias, inclusive pela natureza do seu objeto, pode constituir-se em lugar privilegiado de exercício de boa gestão pública. A premissa de que é necessário "pensar global e agir local”, com acepção estratégica, está acoplada ao fato de que os processos de modernização produziram uma generalização de riscos e 
vulnerabilidades e de que é no nível local que, verdadeiramente, esses problemas ambientais deixam de ser prolixos e expõem desigualmente as populações.

É de pertinência advertir que o conceito de sustentabilidade é um princípio em construção, sobre o qual não há uma supremacia de pensamento. Compete à sociedade a responsabilidade de edificar um desenvolvimento sustentável, assim como a de instituir condições para que amplos setores e atores sociais façam parte dessa construção, ponderando as realidades ecológicas e socioculturais locais, sem esquecer que o atual modelo de crescimento econômico gerou enormes desequilíbrios; se, por um lado, nunca houve tanta riqueza e fartura no mundo, por outro lado, a miséria, a degradação ambiental e a poluição aumentam dia a dia. Em face desta constatação, pressupõe-se educação e persuasão técnica e política para o desenvolvimento, composição de novos alicerces de informação, com a produção e socialização de indicadores ambientais e de desenvolvimento. Necessita-se, também, da aplicação de estratégias hábil de comunicação e marketing social, que propiciem um curso inflexível de informações e o acordar para as possibilidades e vantagens de um processo de desenvolvimento mais solidário e ético.

À luz do conhecimento obtido com este estudo, permite-se inferir que a gestão pública continuamente poderá encontrar os argumentos técnicos e ou científicos para explicar os meios que eventualmente tenha usado, assim como os correlatos resultados conseguidos, contudo, esta não é a problemática principal; o que, de fato faz inferência é o questionamento a respeito do que os gestores poderão conseguir e trazer para dentro da gestão as demandas da sociedade e transformálas em finalidades relevantes.

Assim sendo, e diante dos desafios ambientais, faz-se necessário e imprescindível o emprego de novas formas de avaliação dos impactos ambientais da gestão pública podendo-se para tanto, apoiar-se em métodos e ferramentas para assessorar na resolução de problemas de gestão e na exposição de resultados, em que a mensuração periódica de determinantes ambientais das cidades pode auxiliar na preparação de leis, metas e estratégias de ações públicas, bem como no fortalecimento de organizações comunitárias e ambientais e no aperfeiçoamento dos serviços públicos.

Logo, a disseminação de informações sobre indicadores ambientais de cidades pode se estabelecer em um importante instrumento de incentivo aos governos, cidadãos e entidades no esforço pela modificação social e busca por soluções direcionadas ao desenvolvimento sustentável e à saúde pública das populações. 


\begin{abstract}
The modern societies are tackling various environmental issues like global warming, depletion of non-renewable resources, pollution of water resources, among others. One such issue that stands out is the problem of solid residue. From these considerations, the paper aims to develop a situation analysis of municipal solid residue in the town of Cuite- $\mathrm{PB}$, through the application of the sustainability indicator pressure-state-impact-response (PEIR). In terms of methodology, the study can be characterized as descriptive and exploratory conducted in the form of a case study. Data were obtained from the accomplishment of getting basic data from the social and institutional actors with some kind of bond with the solid residue problem in the city, associated with secondary data analysis and non-participant observation. The results indicate that the total of 36 variables, only six of them were tested positive, corresponding to a percentage of $16,7 \%$, which shows a situation of environmental unsustainability. This situation demands the need for change in public policy, the practices of business management and a higher level of citizenship of the population to reverse this situation.
\end{abstract}

Key-Words: environmental; sustainability; residue solid.

\title{
Referências
}

CAVALCANTI, C. (org.). Desenvolvimento e natureza: estudos para uma sociedade sustentável. 4. ed. São Paulo: Cortez. Recife-PE. Fundação Joaquim Nabuco, 2003.

CMMAD. Nosso futuro comum. New York: ONU, 1987. Disponível em: http://www.scribd.com/doc/12906958/Relatorio-Brundtland-Nosso-Futuro-ComumEm-Portuguese>. Acesso em: 11 jun. 2009.

INSTITUTO BRASILEIRO DE GEOGRAFIA E ESTATÍSTICA. Indicadores de desenvolvimento sustentável. Rio de Janeiro: IBGE, 2002.

MUCELIN, C. A., BELLINI, M. Garbage and perceptible environmental impacts in urban ecosystem. Sociedade e Natureza. (Online), v.20, n.1, 2008, Disponível em: <http://www.scielo.br/scielo.php?pid=S1982-

$45132008000100008 \&$ script $=$ sci_arttext $>$. Acesso em: 10 abr. 2009.

OECD - ORGANIZATION FOR ECONOMIC COOPERATION AND DEVELOPMENT. Environmental indicators: development, measurement and use. Paris: Organização para a Cooperação e o Desenvolvimento Econômico; 2003.

Environmental indicators. Paris: OECD, 1993.

OLIVEIRA, A. S. D. de. Método para a viabilização da implantação de plano de gerenciamento integrado de resíduos sólidos: o caso do município do Rio Grande - RS. Tese de Doutorado. Universidade Federal de Santa Catarina. Programa de Pós-Graduação em Engenharia de Produção. Florianópolis, abril de 2002.

PNUMA. Programa das Nações Unidas para o Meio Ambiente. Projeto Geo Cidades: relatório ambiental urbano integrado - Rio de Janeiro. Rio de Janeiro: PNUMA/MMA/IBAM/ISER/REDEH; 2007.

SACHS, I. Desenvolvimento: includente sustentável sustentado. Garamond Universitária, 2004.

SILVA, H. V. O. O uso de indicadores ambientais para aumentar a efetividade da gestão ambiental municipal [Rio de Janeiro] 2008 XVII, 359 p. 37,0 cm (COPPE, D.Sc., Planejamento Energético, 2008) Tese - Universidade Federal do Rio de Janeiro, COPPE/UFRJ.

SNIS - Sistema Nacional de Informações sobre Saneamento. Diagnósticos do Manejo de Resíduos Sólidos Urbanos. Ministério das Cidades, 2006.

BELLEN H. M. V. Sustainable development: presenting the main measurement methods. Ambiente e Sociedade, v. 7 , n. $1,2004$.

cross ref 
VAN BELLEN, H. M. Indicadores de sustentabilidade: uma análise comparativa. Rio de Janeiro: Editora FGV, 2005.

\section{Dados dos Autores:}

Nome Completo: Sandra Sereide Ferreira da Silva

Filiação institucional: Universidade Federal de Campina Grande - UFCG

Departamento: Programa de Pós-graduação em Recursos Naturais - PPGRN

Função ou cargo ocupado: Doutoranda

Endereço completo para correspondência: Rua 15 de Novembro, 565 - Centro, Cuité-PB. Cep.:

58.175 .000

Telefones para contato: (83) 9987-6286

E-mail: sandrasereide@yahoo.com.br

\section{Nome Completo: Gesinaldo Ataíde Cândido}

Filiação institucional: Universidade Federal de Campina Grande - UFCG

Departamento: Programa de Pós-graduação em Recursos Naturais - PPGRN

Função ou cargo ocupado: Doutor em Engenharia de Produção. Professor Titular em Administração da UFCG

Endereço para correspondência: Rua Esperidião Rosas, 235 - Expedicionários - João Pessoa - PB. CEP: 58.042-070.

Telefones para contato: (83) 3243-1155; (83) 8853-0009

E-mail: gesinaldo@uol.com.br

\section{Nome Completo: Ângela Maria Cavalcanti Ramalho}

Filiação institucional: Universidade Federal de Campina Grande - UFCG

Departamento: Programa de Pós-graduação em Recursos Naturais - PPGRN

Função ou cargo ocupado: Doutora em Recursos Naturais

Endereço para correspondência (Rua Dr Gilvan Barbosa, 133 Catole - Campina Grande-PB

CEP: 58411-046

Telefones para contato: (83) 3331-1168; (83) 9921-9332

E-mail: angelaramalho@oi.com.br

Recebido em: 04/08/2012

Aceito em: 03/10/2012 